\title{
Participações público-privadas: uma análise da aplicabilidade ao caso dos pedágios no Rio Grande do Sul
}

\author{
Nadia Mar Bogoni* \\ Sílvia Letícia Bampi** \\ Alícia Cechin **** \\ Amanda Guareschi*****
}

\section{Resumo}

O objetivo do presente artigo é verificar a partir dos Modelos Econométricos de Função de Regressão Amostral (FRA) e Mínimos Quadrados Ordinários (MQO) o nível de investimentos em rodovias do estado do Rio Grande do Sul (RS/BR), a geração de receitas e despesas dos pedágios como forma de verificar se as Parcerias Público-Privadas (PPP) são atraentes no contexto econômico atual. Aplicou-se a FRA e a MQO para as receitas, despesas e investimentos das concessionárias do estado do Rio Grande do Sul no período de 1998 a 2012. Como resultado, tem-se que a validação do modelo de participação para o Rio Grande do Sul ocorreu por meio da verificação das vantagens desse processo a ambos os lados envolvidos (setor público e privado). Os dados econométricos apresentados identificam a geração de receitas como significativas. Tal fator pode ser considerado como atrativo ao setor privado, cuja finalidade é a obtenção de um lucro maximizado. Por outro lado, as deficiências nos investimentos demonstram a necessidade de aumentar os investimentos de ambos os setores (por intermédio da PPP), para que esses possam complementar o processo de desenvolvimento por meio da infraestrutura de transportes, já que essa tem uma considerável importância para o crescimento econômico da nação.

Palavras-chave: Parcerias público-privadas. Método mínimos quadrados. Pedágios.

\footnotetext{
* Universidade de Passo Fundo, RS, Brasil. E-mail: nbogoni@upf.br

** Universidade de Passo Fundo, RS, Brasil. E-mail:119820@upf.br

*** Universidade de Passo Fundo, RS, Brasil. E-mail: 119802@upf.br

***** Universidade de Passo Fundo, RS, Brasil. E-mail: amandaguareschi@upf.br
}

http://dx.doi.org/10.5335/rtee.v20i43.4596

SUBMISSÃO: 14/07/2014. ACEITE: 04/08/2014. 


\section{Introdução}

A separação entre o público e o privado é uma discussão que vem ganhando espaço desde o início da década de 1990, quando as parcerias público-privadas (PPP's) despontaram como mecanismo complementar para garantir os necessários investimentos em infraestrutura.

No Brasil, a discussão a respeito da adoção de um programa de parcerias iniciou com a lei de PPP, lei n. 11.079/2004. A lei surgiu devido à necessidade de investimentos em infraestrutura e a não disponibilidade de recursos suficientes pelo governo para todos os investimentos necessários. Por meio dessa lei, o governo incentiva à participação do setor privado nos projetos de infraestrutura.

Segundo Oliveira e Cazarini (2011), o processo de deterioração da infraestrutura econômica brasileira torna as parcerias público-privadas (PPP's) uma das mais notáveis fontes alternativas de investimentos. Essa desestruturação tem como resultado a perda de eficiência e de competitividade de diversos setores, dentre esses o setor de transportes. Assim, as PPP's surgem como formas de financiamento para o desenvolvimento de projetos de infraestrutura e serviços à sociedade, ampliando os níveis de investimento.

As PPP's, em sentido amplo, constituem-se em qualquer forma de participação do setor privado em atividades que tradicionalmente estão no âmbito dos governos. Essa definição compreende desde aquelas atividades que podem ser transferidas em sua totalidade ao setor privado, mediante a privatização ou mediante a concessão, nas quais os usuários pagam pelos serviços, até os contratos realizados pelo governo para que o setor privado cumpra uma função muito específica no desenho, na construção, na operação, na manutenção ou no financiamento de uma obra pública, com uma compensação a ser paga diretamente pelo setor público (RUBIO, 2003).

De acordo com Gregg (2006), a América Latina, o Chile e o México foram os pioneiros no uso das PPP's para a provisão de infraestrutura e serviços públicos. Entretanto, nos países em desenvolvimento, a forma de participação privada no setor de transporte mais utilizada é o contrato de concessão. A tendência por contratos de concessão na América Latina pode ser explicada pelo fato de que se acreditava que essa forma contratual era a mais eficiente em diminuir o custo fiscal do setor de transporte, enquanto o setor público mantinha a propriedade dos ativos.

Com a redução do tamanho do estado, a malha rodoviária brasileira passou por modificações no seu modo de financiamento. O processo de concessão de rodovias à iniciativa privada elevou o número de rodovias mantidas, por meio de recursos arrecadados, pela cobrança de pedágios. 
Nesse contexto, a partir das concepções que envolvem as participações das PPP's na atual problemática, a qual engloba os pedágios no estado do Rio Grande do Sul, o objetivo deste artigo é verificar, a partir dos Modelos Econométricos de Função de Regressão Amostral (FRA) e Mínimos Quadrados Ordinários (MQO), o nível de investimentos em rodovias do estado do Rio Grande do Sul (RS/BR) e a geração de receitas e de despesas dos pedágios como forma de verificar se as parcerias público-privadas são atraentes no contexto econômico atual.

A relevância desse estudo encontra-se na importância que o assunto vem ganhando no estado em função da criação de agências reguladoras, bem como as tarifas praticadas nas praças de pedágio.

O trabalho subdivide-se em três seções: a primeira descreve o processo de parceria, situado na legislação vigente; a segunda apresenta os aspectos positivos e negativos desse processo; e a terceira faz uma analogia do atual processo de concessão dos pedágios no Rio Grande do Sul. Com as observações obtidas, são realizadas a avaliação dos resultados e algumas considerações finais.

\section{Referencial teórico}

\subsection{As parcerias público-privadas}

No Brasil, a lei n. 11.079/04 define as Parcerias Público-Privadas como "o contrato administrativo de concessão, na modalidade patrocinada ou administrativa" (BRASIL, 2004).

Para Pereira e Ferreira (2008), a lei n. 11.079, de 31 de dezembro de 2004, instituiu normas gerais para licitação e contratação da chamada Parceria Público-Privada (PPP) no Brasil. Uma PPP pode ser definida como um contrato de concessão, envolvendo pagamentos do setor público ao parceiro privado em contrapartida à oferta privada de serviços públicos. A motivação para tal parceria deve-se ao reconhecimento de que o retorno privado líquido do investimento em bens públicos, em geral, é inferior ao seu retorno social líquido, sendo, portanto, justificável compensar o setor privado pelo investimento nesses bens. De forma resumida, o objetivo principal da lei é fazer uso das PPP's como mecanismo de atração do setor privado para investimentos em infraestruturas.

As Parcerias Público-Privadas (PPP's) tiveram origem na Europa diante dos desafios encontrados pela Inglaterra na busca de caminhos para fomentar investimentos sem comprometer os escassos recursos públicos. O cenário principal dessa 
mudança foi a crise do Estado contemporâneo, especialmente a partir da política de privatizações implantada pelo governo Thatcher, na Inglaterra, destinadas a criar maior espaço para a atuação das forças do mercado, inclusive na realização de obras e na prestação de serviços públicos (PASIN; BORGES, 2003).

Segundo Di Pietro (2008), o modelo de PPP's vem sendo utilizado em vários países, obtendo uma diversidade de resultados. A justificativa para o surgimento de um projeto de lei das parcerias refere-se ao grande sucesso alcançado em países como Inglaterra, Irlanda, Portugal, Espanha e África do Sul. Dentre os objetivos declarados pelo Governo para o aceite das parcerias, relaciona-se a necessidade de realização de obras de infraestrutura para as quais o governo não dispõe de recursos. Dessa forma, constitui a privatização da Administração Pública, que ocorre, como destaca a autora, na transferência para a iniciativa privada das funções do estado, alegando-se a maior eficiência do setor privado.

Conforme Poltronieri (2005), as PPP's surgem como um complemento do marco regulador no que tange à contratação pública, devido à amplitude do contrato que abrange todos os aspectos entre a parceria do setor público e do setor privado, tratando da concessão, da implantação ou da gestão, no todo ou em partes, de serviços de empreendimentos e atividades do setor público em geral.

Para Rubio (2003), as PPP's constituem-se em qualquer forma de participação do setor privado em atividades que tradicionalmente estão na esfera dos governos. $\mathrm{Ou}$ seja, desde aquelas atividades que podem ser transferidas em sua totalidade ao setor privado, mediante a privatização ou mediante a concessão, nas quais os usuários pagam pelos serviços, até os contratos realizados pelo governo para que o setor privado cumpra uma função muito específica no desenho, na construção, na operação, na manutenção ou no financiamento de uma obra pública, com uma compensação a ser paga diretamente pelo setor público.

Peci e Sobral (2007) apresentam uma análise comparativa entre os modelos de Participação Público-Privadas (PPP's) brasileiras e os implementados pelo governo inglês nas últimas décadas. Segundo os autores, o Reino Unido apresentou-se como pioneiro nos processos de reformas estruturais que buscavam o liberalismo econômico, isto é, as participações, neste caso, eram vistas como um método de reduzir a forte presença do estado na economia, utilizando-se, então, do setor privado. Ainda, em comparação com o contexto anglo-saxão, o projeto que mais se aproxima do modelo brasileiro de PPP's é o programa Private Finance Initiative (PFI), que visa encorajar a realização de obras públicas com financiamento privado.

A sustentabilidade dos projetos torna-se chave na conceitualização das PPP's brasileiras. A experiência inglesa (conforme evidencia o Quadro 1) apresenta que o 
recurso às parcerias é mais viável, limitando, assim, o abuso vigente, muitas vezes, no processo de terceirização. Com o objetivo de minimizar a indisponibilidade de recursos públicos futuros, a lei das parcerias define rígidas obrigações de responsabilidade fiscal e consulta pública prévia dos projetos a serem contratados (PECI; SOBRAL, 2007).

Segundo Peci e Sobral (2007), as PPP's, no Brasil, são implantadas na tentativa de sanar problemas de investimento e evidenciar a existência de fatores atrativos para as empresas privadas. Mesmo com uma diversidade de leis e reformas, ainda existem diversas restrições fiscais relacionadas. No próprio governo Lula, essas parcerias foram alvo de discussões políticas, pois eram apresentadas como projetos de "salvação nacional", ou seja, alterariam diretamente os indicadores econômicos, sem desembolso de recursos, nem alteração de metas do superávit primário. Verdadeiramente, pode-se deduzir que o principal fator que influenciou a criação das participações, no Brasil, foi o descaso com a infraestrutura. 
Quadro 1 - Análise comparativa das PPP's no contexto inglês e brasileiro

\begin{tabular}{|c|c|c|c|}
\hline $\begin{array}{l}\text { Componentes de } \\
\text { análise }\end{array}$ & Inglaterra & Brasil & $\begin{array}{l}\text { Vulnerabilidade da } \\
\text { transferência }\end{array}$ \\
\hline Antecedentes & $\begin{array}{l}\text { Prévia desregulamenta- } \\
\text { ção setorial; políticas de } \\
\text { desestatização, regula- } \\
\text { ção e flexibilização da } \\
\text { gestão pública; substi- } \\
\text { tuição das Ryrie Rules. }\end{array}$ & $\begin{array}{l}\text { Prévia desregulamentação } \\
\text { setorial; políticas de deses- } \\
\text { tatização, regulação e flexi- } \\
\text { bilização da gestão pública; } \\
\text { Lei das Concessões; Refor- } \\
\text { ma da Lei das Licitações e } \\
\text { Contratos Administrativos. }\end{array}$ & $\begin{array}{l}\text { Quadro ideológico de di- } \\
\text { reita, embora adotado de } \\
\text { forma consistente, por } \\
\text { governos de esquerda. }\end{array}$ \\
\hline $\begin{array}{l}\text { Fatores de adoção } \\
\text { (segundo ordem de } \\
\text { importância) }\end{array}$ & $\begin{array}{l}\text { Maior eficiência = value } \\
\text { for money; transferência } \\
\text { de riscos; restrições de } \\
\text { ordem fiscal e orçamen- } \\
\text { tária. }\end{array}$ & $\begin{array}{l}\text { Insuficiência de investi- } \\
\text { mentos públicos; restri- } \\
\text { ções de ordem fiscal e } \\
\text { orçamentária. }\end{array}$ & $\begin{array}{l}\text { Falta de sustentabilida- } \\
\text { de e de potencialidade } \\
\text { de aplicação. }\end{array}$ \\
\hline Contexto & $\begin{array}{l}\text { Flexibilidade jurídica; } \\
\text { PPP - parte do progra- } \\
\text { ma PFI; PPP - ampla } \\
\text { gama de instrumentos } \\
\text { jurídicos. }\end{array}$ & $\begin{array}{l}\text { Inflexibilidade jurídica; } \\
\text { Instituição de uma nova } \\
\text { modalidade jurídica. }\end{array}$ & $\begin{array}{l}\text { Necessidade de com- } \\
\text { patibilização com outros } \\
\text { instrumentos jurídicos, } \\
\text { tais como a concessão. }\end{array}$ \\
\hline Controvérsias & $\begin{array}{l}\text { Diminuição de inves- } \\
\text { timentos públicos; for- } \\
\text { mas de contabilizar. }\end{array}$ & $\begin{array}{l}\text { Quadro crescente de falta } \\
\text { de investimentos públi- } \\
\text { cos; vinculação à Lei de } \\
\text { Responsabilidade Fiscal. }\end{array}$ & $\begin{array}{l}\text { Ainda não existem da- } \\
\text { dos para estimar o im- } \\
\text { pacto em termos de in- } \\
\text { vestimentos futuros. }\end{array}$ \\
\hline $\begin{array}{l}\text { Conceitos transfe- } \\
\text { ridos }\end{array}$ & $\begin{array}{l}\text { Value for money, trans- } \\
\text { ferência de riscos; ava- } \\
\text { liação por resultados. }\end{array}$ & $\begin{array}{l}\text { Value for money, transfe- } \\
\text { rência de riscos; avalia- } \\
\text { ção por resultados. }\end{array}$ & $\begin{array}{l}\text { Falta de instrumentos } \\
\text { de aferição do value for } \\
\text { money; limitações na } \\
\text { transferência genuína } \\
\text { de riscos para o setor } \\
\text { privado; falta de expe- } \\
\text { riência. }\end{array}$ \\
\hline $\begin{array}{l}\text { Estrutura organiza- } \\
\text { cional prévia }\end{array}$ & PFI Tasktorce. & $\begin{array}{l}\text { Unidade de Trabalho PPP } \\
\text {-Ministério do Planeja- } \\
\text { mento. }\end{array}$ & $\begin{array}{l}\text { As experiências prévias } \\
\text { em alguns estados e a } \\
\text { complexibilidade da fe- } \\
\text { deração brasileira. }\end{array}$ \\
\hline $\begin{array}{l}\text { Estrutura organiza- } \\
\text { cional implementa- } \\
\text { dora }\end{array}$ & $\begin{array}{l}\text { Partnerships UK; Office } \\
\text { for Governament Com- } \\
\text { merce; comitês gesto- } \\
\text { res de contratos especí- } \\
\text { ficos; consórcio privado. }\end{array}$ & $\begin{array}{l}\text { Comitê gestor das PPP's; } \\
\text { consórcio privado. }\end{array}$ & $\begin{array}{l}\text { Indisponibilidade, quadros } \\
\text { e comitês gestores para } \\
\text { contratos específicos. }\end{array}$ \\
\hline
\end{tabular}

Fonte: Peci; Sobral, 2007, p. 12. 
Conforme Di Pietro (2008), a lei n. 11.079/04 reservou a expressão parceria público-privada para duas modalidades específicas: patrocinada ou administrativa. Para a autora, a patrocinada é a concessão de serviços públicos, precedida ou não de obras públicas, remunerada mediante tarifa paga pelo usuário e contraprestação pecuniária do parceiro público. Por sua vez, a modalidade administrativa é o contrato de prestação de serviços de que a Administração Pública seja a usuária direta ou indireta, ainda que envolva execução de obra ou fornecimento e instalação de bens.

A Figura 1 estabelece a estrutura contratual das parcerias público-privadas.

Figura 1 - Estrutura contratual das PPP's

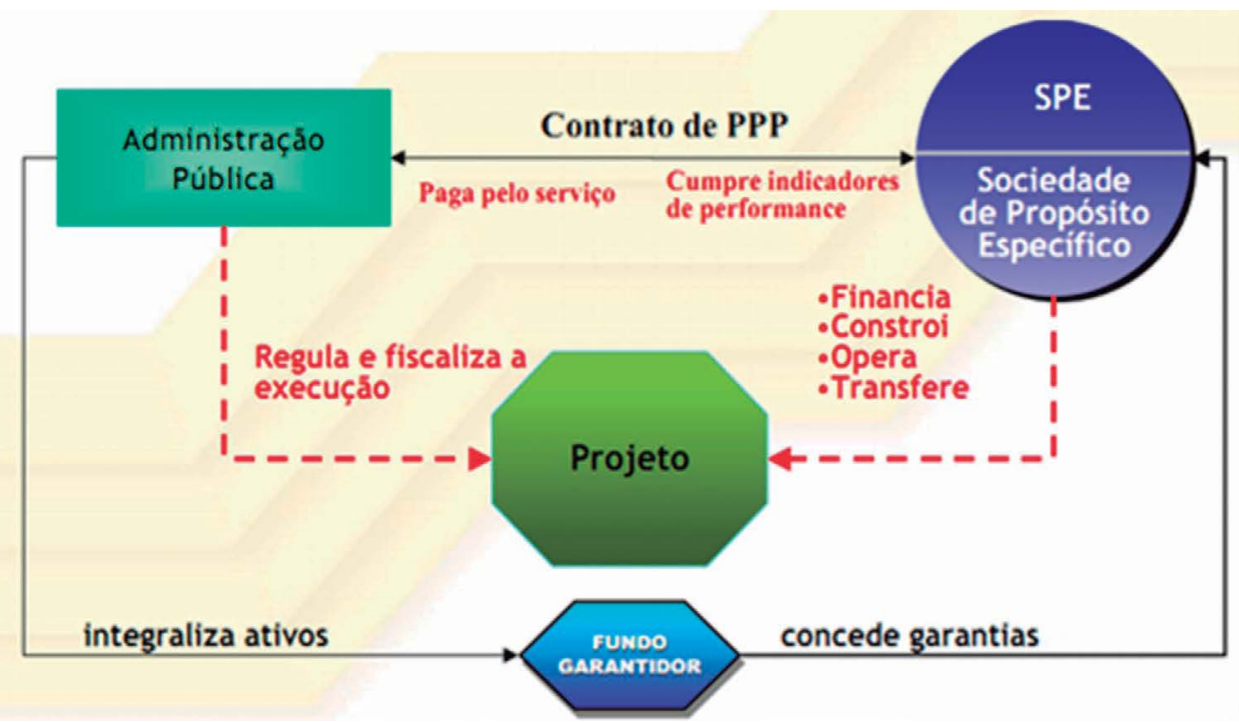

Fonte: Ribeiro, 2004.

De acordo com Portugal (2004), a estrutura contratual das PPP's se estabelece na relação entre Administração Pública e uma sociedade de propósitos específicos (SPE). Entre essas, é regido um contrato de PPP, sendo que a primeira paga pelo serviço e a segunda cumpre os indicadores de desempenho. Define-se um projeto que será regulamentado e fiscalizado pelo setor público e efetivamente realizado pela SPE. Define-se, ainda, um fundo garantidor, que é integralizado pela Administração Pública e que concede as garantias à SPE. 


\subsection{Aspectos contratuais a serem observados nas PPP's}

Nas palavras de Grilo (2008), os aspectos contratuais refletem os arranjos de financiamento, concepções, construções e operações disponíveis e representam os diferentes riscos da partilha de riscos e parceria entre os setores público e privado. Cabe a cada órgão público testar as diferentes opções.

Existem diversos aspectos que precisam ser considerados na análise contratual entre as partes envolvidas. Segundo Grilo (2008), destacam-se o cumprimento de prazos e custos; a velocidade do processo de contratação e implementação da infraestrutura; a flexibilidade e as mudanças esperadas durante as fases de concepção, implantação e operação; a sensibilidade política do serviço; os requisitos de qualidade; o potencial de inovação; o nível de tecnologia instalada no projeto; os níveis de risco e alocação dos riscos do projeto; a complexidade; as economias de escala; a oportunidade para antecipar o início e a conclusão do projeto; os fatores externos ao projeto (ambiente legal e regulatório, estabilidade política, restrições físicas, obtenção de licenças e aprovações, dentre outros); as questões ambientais, comunitárias e de interesse públicos; a necessidade do órgão público; as responsabilidades; a capacidade gerencial do órgão público; os arranjos financeiros; as possibilidades de usos comerciais da infraestrutura; as competências gerenciais do setor privado; o nível de competição pelo mercado e os requisitos de prestação de contas.

\subsection{Restrições e benefícios da cooperação entre o setor público e o setor privado}

Outro aspecto relevante previsto na legislação de Lei de Parcerias é a que trata da repartição dos riscos. Nesse sentido, o art. $4^{\circ}$ da lei estabeleceu a repartição objetiva de riscos nos contratos das parcerias. De acordo com Pinto (2006), esses dispositivos exigem dos juristas uma maior compreensão acerca de futuros riscos no cumprimento desses contratos. Com isso, ganha-se maior seguridade na conclusão desses e também flexibilidade, já que a repartição dos riscos varia conforme as exigências de cada caso, sendo que o parceiro privado concorda com esses parâmetros e conhece-os ainda no contrato. Como enfatiza o autor, resolve-se a questão da abstração de equilíbrio econômico financeiro do contrato, ou seja, um aumento de lucro para o parceiro privado preverá controle de custos, incentivado no próprio arranjo contratual.

Segundo Di Pietro (2008), o art. 5º, incisos III e IV, da lei n. 11.079 prevê que deve ser incluída, nos contratos de parcerias público-privadas, a repartição dos 
riscos entre as partes, inclusive referente ao caso fortuito, à força maior e ao fato príncipe entre outras. A autora indica que, ao contrário de outros tipos de contratos existentes, no caso das PPP's, o inciso III estabelece que, em caso de desequilíbrio econômico, o setor público não arca sozinho com o prejuízo, pelo contrário, ocorre uma repartição do prejuízo e essa repartição já deverá estar disciplinada no contrato.

Conforme Grilo (2008), as PPP's podem ser classificadas de acordo com a transferência de risco e o modelo de risco total, no qual o setor privado assume todos os riscos do projeto. O risco total é comum em concessões onerosas e gratuitas. Outra forma de risco citada pelo autor é a do risco parcial, no qual o governo assume parte do risco da parceria. O risco parcial é utilizado geralmente em concessões administrativas ou patrocinadas. Já o modelo de risco partilhado é feito de forma em que não somente o estado e o parceiro privado, mas também o usuário arque com o risco e a ferramenta usada é a tarifa.

As PPP's têm sido adotadas para controlar os atrasos e os custos elevados nas obras públicas, aumentar a eficiência na gestão dos projetos e reduzir os custos de manutenção e operação dos empreendimentos públicos. Os benefícios mais comuns associados às parcerias são: introdução de inovações na provisão de serviços; alocação de riscos para as partes mais aptas a gerenciá-los; gestão eficiente dos riscos de construção e operação; aumento do desempenho operacional, dentre outros (GRILO, 2008).

Por outro lado, as desvantagens encontram-se nos seguintes aspectos: renegociações frequentes; exigências de garantias onerosas; custos e prazos licitatórios elevados; inflexibilidade contratual; riscos de distorção na alocação de recursos; redução na prestação de contas; necessidade de sigilo comercial dos contratos, custos elevados para a celebração e o monitoramento dos contratos; controle social reduzido; e, dentre outras desvantagens, impacto negativo para o emprego (GRILO, 2008).

\subsection{Um exemplo de PPP: uma análise do caso dos pedágios no Rio Grande do Sul}

A sempre crescente necessidade de alocar recursos para investimentos em outras áreas mais carentes e prioritárias, tais como saúde, educação e segurança gerou a necessidade de inovar na captação de fontes de financiamento para o setor rodoviário, o qual é de fundamental importância para a economia nacional, eis que o Brasil tem a base do transporte de bens e pessoas calcado nesse sistema. Assim, 
na tentativa de reequilibrar a crise institucional interna, a administração trouxe consigo novos esquemas de governança e participação com a inclusão de novos agentes.

O estado abriu espaço para a atuação privada por meio dos processos de privatizações e concessões. A privatização é um ato irrevogável, como complementam. Por sua vez, as concessões estabelecem-se por intermédio de um contrato entre o Poder Público (Poder Concedente) e uma empresa de direito privado (concessionárias). Em virtude desses objetivos, foi criada a Agência Nacional de Transportes Terrestres (ANTT), em 2001, com a finalidade de coordenar, fiscalizar e regular os interesses expressos nos processos. Desse modo, atribuiu-se à agência a elaboração das tarifas de pedágios que consideravam as características da viagem. $\mathrm{O}$ estado do Rio Grande do Sul foi um dos pioneiros a receber concessão de rodovias federais (PECR, 2013).

Segundo Abreu e Silva (2009), em 1992, foi estabelecido o Programa de Pedágio Estadual no Rio Grande do Sul, vinculado ao Departamento Autônomo de Estrada de Rodagem (Daer) o qual, por meio de estudos, verificou as rodovias de maior relevância para a sociedade. Esses trechos foram divididos em polos rodoviários: Polo de Lajeado, Polo de Gramado, Polo Metropolitano, Polo de Santa Maria, Polo de Carazinho, Polo de Santa Cruz do Sul, Polo de Vacaria, Polo de Caxias do Sul e Polo de Pelotas. A Agência Estadual de Regulação dos Serviços Públicos Delegados do Rio Grande do Sul (AGERGS), criada em 1997, ficou responsável pelo acompanhamento dos processos de concessão.

Apesar da resolução do legítimo, junto ao Ministério dos Transportes, a situação não melhorou por completo, já que o governo entrante não cumpriu, novamente, os acordos existentes nos contratos: desta vez, não foram concedidos os reajustes tarifários. Essas medidas unilaterais expressas no descumprimento dos contratos fizeram com que as Concessionárias tivessem que recorrer a financiamentos de longo prazo, junto a entidades financeiras, elevando os custos das concessões e interferindo no equilíbrio dos contratos e na qualidade dos serviços prestados (ABREU; SILVA, 2009, p. 189).

A instabilidade gerada em 1996 aumentou quando, em 2000, as regras de cobranças de pedágios foram alteradas. Conforme destacam Abreu e Silva (2009), essas medidas desequilibraram as concessionárias e esse cenário somente se estabilizaria com as reposições tarifárias e a redução de investimentos entre $2002 \mathrm{e}$ 2004. Foi assinado, assim, um aditivo entre as partes com o objetivo de sanar os desequilíbrios. 


\section{Método de pesquisa}

Do ponto de vista metodológico, a presente pesquisa evidencia características de cunho descritivo, com abordagem quantitativa e de corte seccional.

A pesquisa descritiva, segundo Gil (1995), apresenta como principal objetivo descrever as características de determinada população, fenômeno ou o estabelecimento de relações entre as variáveis.

Em relação à abordagem quantitativa dos dados, essa é explicada em seção específica para maior detalhamento e por se tratar da essência do objetivo do estudo. Hair Jr. et al. (2005, p.100) caracterizam a abordagem quantitativa como sendo "mensurações em que números são usados diretamente para representar as propriedades de algo. Como são registrados diretamente com números, os dados estão em uma forma que se presta para a análise estatística”. Para os autores, a abordagem quantitativa oferece informações resumidas relacionadas a várias características, sendo útil para o mapeamento de tendências.

Richardson (1999, p. 70) caracteriza a abordagem quantitativa "pelo emprego de quantificação tanto nas modalidades de coleta de informações, quanto no tratamento delas por meio de técnicas estatísticas, desde as mais simples, como percentual, média, desvio-padrão, às mais complexas, como coeficientes de correlação, análise de regressão etc.”.

Esse estudo caracteriza-se como sendo de corte seccional (cross-sectional). Babbie (1999) descreve-o como investigação de algum fenômeno, no qual se realiza um corte transversal no tempo, em que são feitas análises detalhadas para fundamentar as observações realizadas uma única vez. Ou seja, serão analisados os dados de séries temporais relacionados aos valores em milhões de reais das receitas, das despesas e dos investimentos, considerados nos pedágios tanto em rodovias federais quanto em rodovias do estado, dos anos de 1998 a 2012 (15 observações).

Quanto ao procedimento da coleta de dados, esse se realizou por meio de pesquisas bibliográficas e documentais dos valores de receita, despesas e investimentos nos Ppdágios localizados no estado do Rio Grande do Sul, tanto em rodovias estaduais quanto em federais. Gil (2002) caracteriza as pesquisas bibliográficas como sendo pesquisa quando desenvolvida a partir das contribuições dos diversos autores acerca de determinado assunto, mediante consulta a livros e periódicos, entre outros. Assim, a pesquisa bibliográfica desse estudo está relacionada aos temas: PPP's, modelo de regressão amostral e dados sobre as rodovias pedagiadas no estado.

Por seu turno, a pesquisa documental tem como fonte de coleta de dados os documentos, escritos ou não, e pode ser feita no momento em que o fato ocorre ou 
depois. Dessa forma, os instrumentos utilizados para esta pesquisa serão a análise de documentos de fontes primárias e de fontes secundárias (MARCONI; LAKATOS, 2002).

A análise dos resultados deriva da aplicação do modelo econométrico de Função de Regressão Amostral (FRA) e pelo uso do Método dos Mínimos Quadrados Ordinários (MQO).

\subsection{Modelo econométrico}

Em relação ao modelo econométrico estimado, utilizaram-se séries temporais relacionadas aos valores em milhões de reais das receitas, das despesas e do investimento. Tais valores foram considerados nos pedágios tanto em rodovias federais como em rodovias do estado, entre os anos de 1998 a 2012 (15 observações). Esses dados são apresentados pela Associação Brasileira de Concessionárias e Rodovias (ABCR), portanto pode-se enumerar que as conclusões aqui obtidas limitam-se aos casos que ocorrem no estado do Rio Grande do Sul.

O objetivo da pesquisa é averiguar se as concepções que envolvem as participações público-privadas podem ser inseridas dentro do processo da atual problemática dos pedágios no Rio Grande do Sul. Com as específicas séries determinadas, procederam-se os testes de raiz unitária, a fim de verificar a ordem de integração dessas, bem como a necessidade de estimações em nível e em primeira diferença. Sob a hipótese nula de raiz unitária, contra a hipótese alternativa de estacionariedade verificou-se que:

a) receita total dos pedágios: série sem a presença de tendência, sem constante e com raiz unitária;

b) receita dos pedágios em rodovias estaduais: série com tendência, com constante e com a presença de raiz unitária;

c) receita dos pedágios em rodovias federais: série com tendência, com constante e com a presença de raiz unitária;

d) investimento total em pedágios: série com a presença de tendência, sem constante e com raiz unitária;

e) investimento em pedágios nas rodovias estaduais: série sem a presença de tendência, com constante e com raiz unitária;

f) investimento em pedágios nas rodovias federais: série sem a presença de tendência, sem constante e com raiz unitária;

g) despesas totais em pedágios: série sem a presença de tendência, sem constante e com raiz unitária;

Teoria e Evidência Econômica - Ano 20, n. 43, p. 337-359, jul./dez. 2014 
h) despesas em pedágios das rodovias estaduais: série sem a presença de tendência, sem constante e com raiz unitária;

i) despesas em pedágios das rodovias federais: série sem a presença de tendência, sem constante e com raiz unitária.

Estimou-se, assim, uma análise de regressão múltipla, que representa a relação entre uma variável dependente por mais de uma variável explicativa, sendo que todas as séries foram utilizadas na primeira diferença, pois apresentavam integração de ordem 1 (I=1). Utilizou-se a função de regressão amostral (FRA) para obtenção de parâmetros estimados. As variáveis utilizadas caracterizam-se como estocásticas, apresentando distribuição de probabilidade, ou seja, sujeitas a um termo de erro. Esse, por sua vez, considera um número n de variáveis que possam vir a interferir no modelo. A regressão apresenta ainda, linearidade nos parâmetros "[...], ou seja, os parâmetros são elevados somente à primeira potência" (GUJARATI; PORTER, 2011, p. 26). A FRA estimada é descrita por:

$$
\hat{Y} \mathrm{i}=\beta_{1}+\beta_{2} \mathrm{X}_{2} \mathrm{i}+\beta_{3} \mathrm{X}_{3} \mathrm{i}+\hat{\mathrm{u} i}
$$

Onde:

$\hat{Y} \mathbf{i}=$ Variável dependente;

$\mathrm{X} 2$ e X3 = Variáveis explicativas;

ûi $=$ Termo de erro;

$\beta_{1}, \beta_{2}$ e $\beta_{3}=$ Parâmetros, sendo que $\beta 1$ fornece a média ou o efeito médio sobre Ŷi de todas as variáveis excluídas do modelo ou o valor médio de $\hat{Y} i$ quando $\mathrm{X}_{2} \mathrm{e}$ X3 são iguais a zero; $\beta_{2}$ e $\beta_{3}$ são chamados de coeficientes de regressão parcial. Então, supondo-se que: o valor médio de ûi seja zero, exista ausência de correlação entre os erros e exista variância homocedástica (constante), a covariância entre ûi e cada variável X seja igual a zero, o viés de especificação esteja ausente e não exista colinearidade exata entre as variáveis explicativas verifica-se que a equação de regressão fornece a média condicional ou o valor esperado de $\mathrm{Y}$ condicional aos valores dados ou fixados das variáveis $\mathrm{X}_{2}$ e $\mathrm{X}_{3}$.

O método utilizado para as estimativas foi o Método dos Mínimos Quadrados Ordinários (MQO). Esse método apresenta a melhor estimativa dos parâmetros, ou seja, que o somatório dos erros estimados em relação ao somatório da distância do Y estimado ao Y real ( $\Sigma$ ûi $=\Sigma$ (yi $-\hat{y} i)$ ), seja a menor possível, conforme Gujarati e Porter (2011). Quanto à forma funcional do modelo, utilizou-se o modelo logaritimizado, sendo que as três variáveis são utilizadas na forma logarítmica e serão analisadas em valores percentuais. Dessa forma, os modelos observados no artigo são definidos por: 
1. $\log ($ Receita_totais $)=\beta_{1}+\log ($ Receita_rs $) X_{1}+\log ($ Receita_federal $) X_{2}$

\begin{tabular}{|l|c|c|c|}
\cline { 2 - 4 } \multicolumn{1}{c|}{} & Constante & Receitas rodovias estaduais (RS) & Receitas rodovias federais \\
\hline Coeficientes & $-2,04$ & 7,12 & 0,003 \\
\hline Ep & 0,86 & 1,61 & 0,002 \\
\hline$P$ & 0,04 & 0,001 & 0,25 \\
\hline$R^{2}$ & 0,64 & & \multicolumn{1}{c|}{} \\
\hline
\end{tabular}

2. $\log ($ Investimento_totais $)=\beta_{1}+\log ($ Investimento_rs $) X_{1}+\log ($ Investimento_federal $) X_{2}$

\begin{tabular}{|l|c|c|c|}
\cline { 2 - 4 } \multicolumn{1}{c|}{} & Constante & Investimento rodovias estaduais (RS) & Investimento rodovias federais \\
\hline Coeficientes & 0,09 & 0,09 & 0,15 \\
\hline Ep & 0,07 & 0,08 & 0,17 \\
\hline $\mathrm{P}$ & 0,25 & 0,32 & 0,40 \\
\hline $\mathrm{R}^{2}$ & 0,22 & \multicolumn{2}{c}{} \\
\hline
\end{tabular}

3. $\log ($ Desesas_totais $)=\beta_{1}+\log ($ Despesa_rs $) X_{1}+\log ($ Despesa_federal $) X_{2}$

\begin{tabular}{|l|c|c|c|}
\cline { 2 - 4 } \multicolumn{1}{c|}{} & Constante & Receitas rodovias estaduais (RS) & Receitas rodovias federais \\
\hline Coeficientes & 0,06 & $-0,06$ & 0,55 \\
\hline Ep & 0,01 & 0,06 & 0,07 \\
\hline$P$ & 0,003 & 0,28 & 0,000 \\
\hline$R^{2}$ & 0,85 & \multicolumn{2}{c}{} \\
\cline { 1 - 4 } & \multicolumn{2}{|c}{} \\
\cline { 1 - 4 }
\end{tabular}

A utilização dos modelos tem como objetivo avaliar as modificações de infraestrutura (investimentos), as implicações nas variações de receitas e despesas dos pedágios das rodovias do Rio Grande do Sul. Da mesma forma, foi observada a significância dessas variáveis para as rodovias federais (BR) e correlacioná-las aos totais do país. Os resultados obtidos, descritos a seguir, tornam-se congruentes em relação ao objetivo desse artigo. 


\section{Análise dos resultados}

Os dados apresentados abaixo verificam a geração de receitas, despesas e 0 nível de investimentos nos pedágios do Rio Grande do Sul. A análise do artigo correlaciona principalmente o período de 2002 a 2012.

A arrecadação de receitas relacionadas aos pedágios no Rio Grande do Sul, localizados em rodovias estaduais, apresentava-se em 129,674 milhões de reais em 2002. Em 2005, esses valores eram de 238,419 milhões de reais. Em 2009, 367,960 milhões de reais e, em 2012, 515,082 milhões de reais. Verifica-se o significativo crescimento na arrecadação ao longo desses períodos, em contrapartida aos pedágios federais que já em 2012 apresentavam um recolhimento de 3.191,044 milhões de reais em pedágios de rodovias federais, sendo que, no mesmo ano, o valor total recolhido foi de 13.399,179 milhões de reais. Considera-se ainda que a extensão da rede rodoviária brasileira pavimentada, conforme dados do Departamento nacional de infraestrutura de transportes (DNIT-DPP) e da /Coordenação de Planejamento (CGPLAN) disponibilizados pela Associação Brasileira de Concessionárias de Rodovias (ABCR) situava-se, em 2012, em 219.846,500 km. Dessas, 7,4\% apresentavam-se sob processo de concessão. 
Tabela 1 - Receita de pedágios em R\$ milhões: período de 1998 a 2012 no estado do Rio Grande do Sul

\begin{tabular}{|c|c|c|c|c|c|c|}
\hline \multicolumn{7}{|c|}{ Receita de pedágio - $\mathrm{R} \$$ milhões } \\
\hline Ano & Total & Federais & São Paulo & Paraná & $\begin{array}{c}\text { Rio Grande } \\
\text { do Sul }\end{array}$ & $\begin{array}{c}\text { Demais } \\
\text { programas }\end{array}$ \\
\hline 1995 & 0,000 & 0,000 & & & & \\
\hline 1996 & 115,351 & 115,351 & & & & \\
\hline 1997 & 316,560 & 312,970 & & & & 3,590 \\
\hline 1998 & 907,720 & 380,074 & 355,725 & 91,529 & 21,242 & 59,150 \\
\hline 1999 & $1.487,247$ & 404,398 & 747,321 & 164,951 & 81,224 & 89,353 \\
\hline 2000 & $1.886,807$ & 466,363 & 997,201 & 227,912 & 88,570 & 106,761 \\
\hline 2001 & $2.511,638$ & 541,649 & $1.366,239$ & 355,724 & 107,916 & 140,110 \\
\hline 2002 & 2898,38 & 612,01 & 1580,58 & 403,51 & 129,67 & 172,61 \\
\hline 2003 & 3399,90 & 682,38 & 1872,82 & 485,01 & 172,10 & 187,58 \\
\hline 2004 & 4263,86 & 842,56 & 2447,27 & 543,99 & 220,12 & 209,94 \\
\hline 2005 & 4814,44 & 895,51 & 2798,37 & 639,88 & 238,42 & 242,25 \\
\hline 2006 & 5325,16 & 1050,75 & 3021,38 & 724,63 & 264,19 & 264,22 \\
\hline 2007 & 5917,78 & 1157,82 & 3332,27 & 834,14 & 303,25 & 290,29 \\
\hline 2008 & 6758,45 & 1301,00 & 3857,81 & 908,86 & 335,13 & 355,65 \\
\hline 2009 & 8225,46 & 1896,91 & 4532,05 & 1015,63 & 367,96 & 412,92 \\
\hline 2010 & 10365,52 & 2351,42 & 5940,04 & 1199,33 & 422,14 & 452,58 \\
\hline 2011 & 12103,64 & 3018,30 & 6659,12 & 1376,66 & 445,43 & 604,12 \\
\hline 2012 & 13399,18 & 3191,04 & 7491,83 & 1531,80 & 515,08 & 669,42 \\
\hline
\end{tabular}

* Valores ajustados para o número de Concessionárias em operação no ano.

Fonte: Associação Brasileira de Concessionárias e Rodovias (ABCR).

O Registro Nacional de Transportes Rodoviários de Carga (ANTT) apresentava em 2012, conforme a ABCR, uma frota de 1.820 .734 veículos. O transporte rodoviário representa $61,10 \%$ do total que inclui ferroviários, aquaviários, dutoviários e aéreos (dados da Revista CNT/2012, disponibilizados pela ABCR). Em observância a esses valores, os investimentos relativos às rodovias federais mantinham um crescimento até o ano de 2009, conforme tabela abaixo. Em 2010, tiveram uma 
redução de cerca de $13,28 \%$, retomando o crescimento nos períodos seguintes. Em relação ao Rio Grande do Sul, houve consecutiva redução entre os anos de 2009 e de 2010 e retomada do crescimento nos períodos seguintes.

Tabela 2 - Investimentos em R\$ milhões: período de 1998 a 2012 no estado do Rio Grande do Sul

\begin{tabular}{|c|c|c|c|c|c|c|}
\hline \multicolumn{7}{|c|}{ Investimentos - $\mathrm{R} \$$ milhões } \\
\hline Ano & Total & Federais & São Paulo & Paraná & $\begin{array}{l}\text { Rio Grande } \\
\text { do Sul }\end{array}$ & $\begin{array}{c}\text { Demais } \\
\text { programas }\end{array}$ \\
\hline 1995 & 1,283 & 1,283 & & & & \\
\hline 1996 & 260,421 & 183,559 & & & & 76,862 \\
\hline 1997 & 220,961 & 184,639 & & & & 36,322 \\
\hline 1998 & $1.015,780$ & 336,853 & 176,774 & 279,647 & 156,506 & 66,000 \\
\hline 1999 & 794,525 & 282,237 & 421,341 & 21,482 & 11,914 & 57,551 \\
\hline 2000 & $1.524,315$ & 191,109 & $1.110,061$ & 120,095 & 14,629 & 88,421 \\
\hline 2001 & $1.744,863$ & 155,815 & $1.249,642$ & 217,987 & 52,575 & 68,844 \\
\hline 2002 & 1560,42 & 106,06 & 1042,05 & 278,52 & 49,86 & 83,92 \\
\hline 2003 & 1024,91 & 90,48 & 664,82 & 157,31 & 79,42 & 32,87 \\
\hline 2004 & 1034,17 & 143,51 & 694,74 & 90,13 & 89,26 & 16,54 \\
\hline 2005 & 1315,27 & 230,68 & 799,08 & 135,72 & 89,52 & 60,28 \\
\hline 2006 & 1451,33 & 201,14 & 1006,68 & 141,43 & 52,11 & 49,96 \\
\hline 2007 & 1424,63 & 238,62 & 935,92 & 179,25 & 28,42 & 42,43 \\
\hline 2008 & 2460,53 & 908,59 & 1149,47 & 203,43 & 117,86 & 81,19 \\
\hline 2009 & 3075,30 & 1111,72 & 1604,67 & 244,76 & 63,70 & 50,45 \\
\hline 2010 & 3512,86 & 964,06 & 1977,53 & 303,86 & 57,09 & 210,32 \\
\hline 2011 & 3825,82 & 1510,20 & 1620,76 & 276,73 & 145,75 & 272,39 \\
\hline 2012 & 4634,22 & 1858,74 & 2113,62 & 300,54 & 152,04 & 209,28 \\
\hline
\end{tabular}

* Valores ajustados para o número de Concessionárias em operação no ano.

Fonte: Associação Brasileira de Concessionárias e Rodovias (ABCR).

Os gastos operacionais com pedágios no estado apresentaram queda nos últimos dois anos (2010-2012). Em relação às rodovias federais, esse mesmo período apresentou um acréscimo de cerca de 7,61\% nas despesas. O estado de São Paulo é o que apresenta as maiores despesas operacionais em relação aos pedágios do país, e, segundo a ABCR, tem o maior tráfego pedagiado, seguido pelos estados do Paraná e do Rio Grande do Sul. 
Tabela 3 - Despesas operacionais em R\$ milhões: período de 1998 a 2012 no estado do Rio Grande do Sul

\begin{tabular}{|c|c|c|c|c|c|c|}
\hline \multicolumn{7}{|c|}{ Despesas operacionais - $\mathrm{R} \$$ milhões } \\
\hline Ano & Total & Federais & São Paulo & Paraná & $\begin{array}{l}\text { Rio Grande } \\
\text { do Sul }\end{array}$ & $\begin{array}{c}\text { Demais } \\
\text { programas }\end{array}$ \\
\hline 1995 & 3,863 & 3,863 & & & & \\
\hline 1996 & 115,066 & 113,261 & & & & 1,805 \\
\hline 1997 & 173,089 & 157,890 & & & & 15,199 \\
\hline 1998 & 770,285 & 242,880 & 315,574 & 119,760 & 46,197 & 45,874 \\
\hline 1999 & 636,109 & 157,201 & 326,477 & 89,157 & 38,356 & 24,918 \\
\hline 2000 & 830,458 & 214,765 & 435,235 & 108,071 & 42,594 & 29,793 \\
\hline 2001 & 988,095 & 250,798 & 478,424 & 167,110 & 46,425 & 45,338 \\
\hline 2002 & 1070,59 & 275,82 & 499,86 & 167,59 & 68,61 & 58,70 \\
\hline 2003 & 1264,72 & 332,61 & 576,16 & 216,29 & 68,13 & 71,53 \\
\hline 2004 & 1457,96 & 361,06 & 701,04 & 252,04 & 75,49 & 68,33 \\
\hline 2005 & 1623,04 & 384,38 & 784,00 & 289,87 & 79,16 & 85,62 \\
\hline 2006 & 1757,23 & 431,10 & 772,71 & 335,62 & 128,03 & 89,77 \\
\hline 2007 & 1981,75 & 458,64 & 914,40 & 349,40 & 159,18 & 100,13 \\
\hline 2008 & 2244,09 & 571,89 & 1048,84 & 364,79 & 119,80 & 138,77 \\
\hline 2009 & 3001,58 & 828,01 & 1538,60 & 403,75 & 115,42 & 115,79 \\
\hline 2010 & 3296,72 & 1110,44 & 1450,93 & 397,83 & 170,49 & 167,04 \\
\hline 2011 & 3926,12 & 1351,70 & 1724,46 & 502,37 & 143,33 & 204,25 \\
\hline 2012 & 4383,42 & 1454,61 & 2069,66 & 487,08 & 123,14 & 248,94 \\
\hline
\end{tabular}

* Valores ajustados para o número de Concessionárias em operação no ano.

Fonte: Associação Brasileira de Concessionárias e Rodovias (ABCR).

Analisando os dados de receita (Tabela 1) nas rodovias do Rio Grande do Sul, pode-se observar o quanto estes interferem nos valores referentes aos totais do governo. Econometricamente, as receitas de pedágio do RS, quando variadas em $1 \%$, inferem uma variação no mesmo sentido das receitas totais de pedágio em $7,12 \%$. Essa variação representa que esses valores arrecadados modificam significativamente os valores totais, aos níveis de significância observados $(1 \%, 5 \%$ e 10\%). Os patamares de desenvolvimento econômico, observados nos últimos anos no estado, verificam-se, ao passo que a arrecadação de valores dos pedágios cresceu 
gradativamente. Observando-se um aumento significativo nessas arrecadações no período de 2011 para 2012 , cerca de $15,64 \%$, em contrapartida a um aumento anterior, 2010 para 2011, de apenas 5,52\%. Quando em comparação aos valores relativos dos pedágios em rodovias federais, observa-se inversão desse quadro, ou seja, o crescimento maior na arrecadação de receitas $(28,36 \%)$ foi referente ao período de 2010 para 2011.

Em relação aos investimentos (Tabela 2), foi possível constatar que o percentual de investimentos feitos referente aos pedágios no Rio Grande do Sul torna-se relativamente insignificante em relação aos investimentos totais que conglomeram os investimentos federais e os dos demais estados. Ou seja, uma variação de $1 \%$ nos investimentos em pedágios nas rodovias estaduais no RS acarretaria uma variação de $0,09 \%$, considerando-se os investimentos em pedágios federais do estado constante. Em relação ao período de 2010 para 2011, ocorreu uma elevação nos valores referente aos investimentos nos pedágios do estado (rodovias estaduais) de cerca de $155 \%$ em contrapartida a $4,32 \%$ de aumento referente a 2011 para 2012 . Essas observações demonstram que os investimentos nessa área ainda são insuficientes, apesar do elevado crescimento em alguns períodos observados.

Ainda, em relação às despesas operacionais (Tabela 3), pode-se verificar que as despesas relacionadas aos pedágios do Rio Grande do Sul não têm interferência significativa nas despesas totais. Uma variação de $1 \%$ nas despesas operacionais com pedágios do estado implica em uma variação no sentido oposto de $0,06 \%$ nas despesas operacionais totais com pedágios. Assim, em 2012, essas despesas (estado) representavam 2,81\% das despesas totais do Brasil, enquanto as despesas com rodovias federais representavam $33,18 \%$ das totais. Novamente, destaca-se que os gastos em pedágios nas rodovias estaduais do Rio Grande do Sul devem ser reavaliados, pois representam atualmente uma parcela relativamente pequena em comparação aos gastos das rodovias federais.

A validação do modelo de participação para o Rio Grande do Sul ocorre por meio da verificação das vantagens desse processo a ambos os lados envolvidos. Os dados econométricos apresentados identificam a geração de receitas como significativas e esse fator pode ser considerado como atrativo ao setor privado, cuja finalidade é a obtenção de um lucro maximizado. Do outro lado, as deficiências nos investimentos referentes apresentam a necessidade, por parte do setor público, de serviços que venham a complementar o processo de desenvolvimento por meio da infraestrutura. Esse complemento dar-se-á pelo setor privado pela cooperação estabelecida em uma PPP e que são de fundamental importância para o crescimento econômico da nação. 


\section{Considerações finais}

A adoção do modelo de parcerias público-privadas no Brasil justifica-se como uma tentativa do governo de despertar a atratividade do setor privado para a viabilização de alguns projetos. Esse desinteresse deve-se, principalmente, à extensiva carga tributária brasileira, como também aos elevados patamares dos juros presentes nos períodos analisados. A necessidade de uma infraestrutura qualificada torna-se cada vez mais presente, ao passo que as economias tornam-se cada vez mais desenvolvidas. Dessa forma, as parcerias apresentam-se efetivas, à medida que se verifica a necessidade de investimentos (privado) e de maior transparência na operacionalização desses (público).

Assim, o artigo objetivou, a partir das concepções que envolvem as participações das PPP's na atual problemática que envolve os pedágios no estado do Rio Grande do Sul, verificar, por meio dos Modelos Econométricos de Função de Regressão Amostral (FRA) e Mínimos Quadrados Ordinários (MQO), o nível de investimentos em rodovias do estado (RS/BR), a geração de receitas e de despesas dos pedágios como forma de verificar se as parcerias público-privadas são atraentes no contexto econômico atual.

Como resultado, tem-se a validação do modelo de participação para o Rio Grande do Sul, o qual ocorreu a partir da verificação das vantagens desse processo a ambos os lados envolvidos (setores público e privado). Os dados econométricos apresentados identificam a geração de receitas como significativas e esse fator pode ser considerado como atrativo ao setor privado, cuja finalidade é a obtenção de um lucro maximizado. Por outro lado, as deficiências nos investimentos demonstram a necessidade de aumentar os investimentos de ambos os setores (por intermédio da PPP), para que esses possam complementar o processo de desenvolvimento da infraestrutura de transportes, uma vez que essa apresenta uma considerável importância para o crescimento econômico da nação. 


\title{
Public-private equity: A Case Analysis of the Applicability of Tolls in Rio Grande do Sul
}

\begin{abstract}
Abstract: The purpose of this article is to verify from Econometric Models of Regression Function Sample (FRA) and Ordinary Least Squares (OLS) the level of investment in highways of the State of Rio Grande do Sul (RS/BR), the generation revenue and expenditure of Tolls as a way to verify that the Public-Private Partnerships (PPP) are attractive in the current economic context. Applied to FRA and OLS for Revenue, Expenditure and Investment Dealers of the State of Rio Grande do Sul from 1998 to 2012. As a result, there is a validation of the contribution to Rio Grande do Sul model occurred by verifying the advantages of this process to both sides involved (public and private sectors). The econometric data presented identify revenue generation as significant, this factor can be considered as attractive to the private sector, whose purpose is to obtain a maximized profit. Furthermore, deficiencies in investments demonstrate the need for increased investment in both sectors (through PPP) so that they can complement the process of development through transportation infrastructure, since it has considerable importance for economic growth of the nation.
\end{abstract}

Keywords: Public-private partnerships. Least squares method. Tolls.

\section{Inversiones público y privado: un análisis de la aplicabilidad al caso de peaje en Rio Grande do Sul}

\section{Resumén}

Resumen: El propósito de este artículo es verificar desde modelos econométricos de la Muestra de funciones de regresión (FRA) y mínimos cuadrados ordinarios (OLS) el nivel de inversión en carreteras del Estado de Rio Grande do Sul (RS/BR), la generación de ingresos y los gastos de peajes como una manera de verificar si las Asociaciones PúblicoPrivadas (APP) son atractivas en el contexto económico actual. Se utilizó la FRA y los OLS para Ingresos, Gastos y Distribuidores de inversión del estado de Rio Grande do Sul del período de 1998-2012. El resultado obtenido es que la validación del modelo para la participación de Rio Grande do Sul se produjo a través de la verificación de las ventajas de este proceso para las dos partes implicadas (sectores público y privado). Datos econométricos presentados identifican la generación de ingresos como significativa, este factor puede ser considerado como atractivo para el sector privado, cuyo objetivo es obtener un beneficio máximo. Por otra parte, las deficiencias en las inversiones demostran la necesidad de una mayor inversión en ambos sectores (a través de PPP), de manera que puedan complementar el proceso de desarrollo a través de la infraestructura de transporte, puesto que tiene una gran importancia para el crecimiento económico de la nación.

Palabras clave: Alianzas público-privado. Método de mínimos cuadrados. Peajes. 


\section{Referências}

ABOIM, S. Do público e do privado: uma perspectiva de gênero sobre uma dicotomia moderna. Estudos Feministas, Florianópolis, v. 20, n. 1, p. 95-117, jan./abr. 2012. Acesso em: 7 abr. 2013.

ABREU, B. V.; SILVA, T.C. Novos paradigmas para Administração Pública: análise de processos de concessão e parceria público-privada em rodovias brasileiras. Administração pública e gestão social, Viçosa, v. 1, n. 2, p.175-179, abr./jun. 2009.

ALMEIDA SANTOS, L. W. M. Parcerias público-privadas: o controle externo atuando em críticas e polêmicas fronteiras. Revista do Tribunal de Contas da União, Brasília, v. 36, n. 107, p. 75-82, jan./dez. 2006.

PEREIRA, R.A. C; FERREIRA, P.C. Efeitos de crescimento e bem-estar da lei de parceria público-privada no Brasil. Revista Brasileira de Economia (RBE), Rio de Janeiro, v. 62, n. 2, p. 207-219, abr.jun. 2008.

ASSOCIAÇÃO BRASILEIRA DE CONCESSIONÁRIAS DE RODOVIAS. Disponível em: <http:// www.abcr.org.br>. Acesso em: 18 maio 2013.

BABBIE, Earl. Métodos de pesquisas de survey. Belo Horizonte: Ed. UFMG, 1999.

BRASIL. Lei n. 11.079, de 30 de dezembro de 2004. Presidência da República. Brasília. Disponível em: <http://www.planalto.gov.br>. Acesso em: 18 maio 2013.

DI PIETRO, M. S. Z. Parcerias na administração pública: concessão, permissão, franquia, terceirização, parceria público-privada e outras formas. 6. ed. São Paulo: Editora Atlas, 2008, p. 142-175.

GIL, A. C. Como elaborar projetos de pesquisa. 4. ed. São Paulo: Atlas, 2002.

GREGG, D. S. Parcerias público-privadas como alternativa para mitigar o problema de Hold UP em investimentos de infraestrutura no setor ferroviário: um estudo de caso. Dissertação (Mestrado em Finanças e Economia Empresarial) - Fundação Getúlio Vargas - FGV, Rio de Janeiro, 2006.

GRILO, L. M. Modelo da análise da qualidade do investimento em projetos de parceria público-privada (PPP). Tese (Doutorado em Engenharia da Construção Civil e Urbana) - Escola Politécnica da UPS, São Paulo, 2008.

GUJARATI, D. N., PORTER, D, C. Econometria básica. 5 ed. São Paulo: AMGH, 2011.

HAIR JR, J. F. et al. Fundamentos de métodos de pesquisa em administração. Porto Alegre: Bookman, 2005.

MARCONI, M. A; LAKATOS, E. M. Metodologia do trabalho científico: procedimentos básicos, pesquisa bibliográfica, projeto e relatório, publicações e trabalhos científicos. 4. ed. São Paulo: Atlas, 2002.

OKIN, S. M. Gênero, o público e o privado. Estudos Feministas, Florianópolis, v. 16, n. 2, p. 305332, maio/ago. 2008.

OLIVEIRA, S. R. M.; CAZARINI, E.W. Riscos em projetos de parcerias público-privadas. In: SIMPÓSIO DE ADMINISTRAÇÃO DA PRODUÇÃO LOGÍSTICA E OPERAÇÕES INTERNACIONAIS, XIV, Anais... 2011. São Paulo: FGV, 2011, p. 1-14. Disponível em: <http://www.simpoi. fgvsp.br/>. Acesso em: 7 abr. 2013. 
PASIN, J. A. B.; BORGES, L. F. X. A nova definição de parceria público-privada e sua aplicabilidade na gestão de infraestrutura pública. Revista do BNDES, Rio de Janeiro, v. 10, n. 20, p. 173-196, dez. 2003.

PECI, A; SOBRAL, F. Parcerias público-privadas: análise comparativa das experiências britânica e brasileira. Cadernos EBAPE.BR - Fundação Getúlio Vargas, São Paulo, v. 5, n. 2, p. 1-14, jun. 2007.

PINTO, M. B. A função das econômicas das PPP's. Revista Eletrônica de Direito administrativo Econômico, Salvador, n. 2, p. 1-11, maio/jul. 2005.

PINTO, M. B. Repartição de Riscos nas parcerias público-privadas. Revista do BNDES, Rio de Janeiro, v. 13, n. 25, p. 155-182, jun. 2006.

POLTRONIERI, R. Parceria público privada e a atuação administrativa: reflexões sobre a instituição de parcerias entre Administração Pública e o setor privado e os contratos administrativos aplicáveis a esta forma especial de concessão de serviço público. São Paulo: Editora Juarez Oliveira, 2005.

PROGRAMA ESTADUAL DE CONCESSÃO RODOVIÁRIA (PECR) n. 37, Porto Alegre, abril, 2013.

RIBEIRO, M. P. Parcerias público-privadas: o projeto de lei em tramitação. Ministério do Planejamento, Orçamento e Gestão. Rio de Janeiro, out./ 2004. Disponível em: <http://www.planejamento.gov.br>. Acesso em: 18 maio 2013.

RICHARDSON, R. J. et al. Pesquisa social: métodos e técnicas. 3 ed. São Paulo: Atlas, 1999.

RUBIO, L A. Asociación público-privada en la provisión de servicios de infraestructura: conceptualización y formas de financiamiento. Rio de Janeiro: Seminário Internacional Asociación Público-Privada, nov. 2003. Disponível em: <http://federativo.bndes.gov.br >. Acesso em: 16 maio 2013. 